\title{
Weighted scalar constraints capture the typology of loanword adaptation*
}

\author{
Brian Hsu and Karen Jesney \\ University of North Carolina at Chapel Hill and Carleton University
}

\section{Introduction}

The fact that phonological generalizations do not always affect all lexical items in a language uniformly is an important concern for phonologists. Loanword patterning is of particular interest in this context, having the potential to reveal key generalizations about the organization of the phonological grammar and its interaction with the lexicon (Saciuk 1969; Itô \& Mester 1995, 1999; Paradis \& LaCharité 1997, 2001; Kenstowicz \& Suchato 2006; Smith 2006; Jurgec 2010; among others).

This paper discusses three basic ways in which loanwords pattern differently than native vocabulary, with a specific focus on the implicational relationships that hold among generalizations that apply at different degrees of nativization. We argue that the overall typology is best modeled if constraints are weighted as in Harmonic Grammar (HG; Legendre, Miyata \& Smolensky 1990; Smolensky \& Legendre 2006), and violation scores are scaled according to degree of nativization. This approach correctly and simply predicts the attested implicational patterns, while an analysis in Optimality Theory (Prince \& Smolensky 1993) requires a range of additional complications.

\section{Implicational process application across loanword strata}

Loanwords are often subject to different phonological generalizations than native vocabulary, and subclasses of loanwords that differ in their degree of nativization can show further distinctions in their patterning. These patterns suggest that the lexicon is organized into a core-periphery structure (Saciuk 1969; Holden 1976; Paradis \& Lebel 1994; Itô \& Mester 1995; Davidson \& Noyer 1997), in which individual subclasses (a.k.a. lexical strata) exist in a nested relationship. The patterning of individual strata is not arbitrary; instead, phonological generalizations that apply within the core vary in how far they extend into the less nativized periphery (Holden 1976).

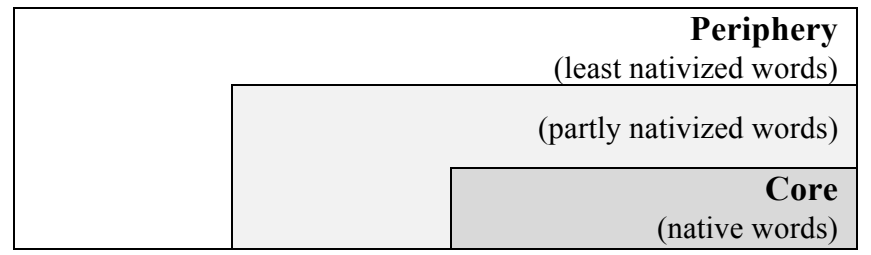

Figure 1: Core-periphery model of the lexicon

While the core-periphery structure is most commonly associated with patterns where markedness restrictions that hold in the core weaken in increasingly peripheral strata, this is not the only possible pattern. This section presents three basic ways in which degree of nativization affects the phonological patterning of loanwords (Kenstowicz 2005), all of which show an implicational structure.

\footnotetext{
* Thanks to Eric Baković, Ryan Bennett, Reed Blaylock, Lev Blumenfeld, Robin Karlin, Ryan Hearn, Sharon Inkelas, Lilla Magyar, Kevin McMullin, Elliott Moreton, Charlie O’Hara, Sharon Rose, Stephanie Shih, Caitlin Smith, Jen Smith, Juliet Stanton, Anne-Michelle Tessier, Rachel Walker, Colin Wilson and the audiences at USC, WCCFL 34 and the LSA 2017 for feedback on various iterations of this work.
} 
2.1 Superset at periphery In the case of superset-at-periphery patterns, loanwords are subject to fewer restrictions than native vocabulary. That is, structures that are banned in native words are permitted in loanwords. This can be observed in the patterning of $[\mathrm{I}]$ and consonant clusters in Oshikwanyama (Bantu), as described by Steinbergs (1985). Neither of these structures is permitted in native words; while $[x]$ and clusters are adapted in older borrowings (1-2), they are permitted in newer ones (3-4). (Word-initial $[\mathrm{o}]$ in the borrowed forms is a noun class prefix.)

$$
\begin{aligned}
& \text { Old loans: [..] repair by substitution } \\
& \text { Eng. seraph }>\text { [šelafi] } \\
& \text { Ger. radio }>\text { [oladijo] }
\end{aligned}
$$$$
\text { Newer loans: No repair of }[. \mathrm{I}]
$$$$
\text { Eng. beer }>\text { [obira] }
$$

\author{
Old loans: cluster repair by epenthesis \\ Eng. farm $>$ [ofalama] \\ Ger. brot $>$ [ombolota] 'bread'
}

Newer loans: No repair of clusters

Eng. ice cream $>$ [oajskrima]

Looking at loanwords that contain the two marked structures reveals an implicational relationship between the repair processes. As Steinbergs notes, if cluster simplification applies in a given word, [I] must be repaired by substitution; the opposite, however, is not true. While the language contains borrowings that retain clusters but substitute [1] for [.]], such as [blækbolda] 'blackboard', no borrowings contain simplified clusters and non-substituted $[\mathrm{I}]$ - i.e., *[oaysikirima] 'ice cream' is not a possible borrowed form. In terms of the core-periphery structure, this indicates that consonant clusters are tolerated in strata closer to the core than is $[\mathrm{I}]$.

$\begin{array}{lll}(\text { core }) & \text { Eng. farm }>\text { [ofalama] } \\ \uparrow & \text { Eng. blackboard }>\text { [blækbolda] } \\ \text { (periphery) } & \text { Eng. ice cream }>\text { [oajskrima] }\end{array}$

$*[\mathrm{I}],{ }^{*} \mathrm{CC}$ enforced

*[.] enforced

Impossible nativization effects - like the impermissibility of *[oaysikirima] in Oshikwanyama provide strong evidence for the nested organization of strata posited by the core-periphery model. For the superset at periphery case, the generalizations can be stated as in (6).

Superset at periphery:

- If a structure $M$ is tolerated within words of a given stratum, $M$ is tolerated for words in all more peripheral strata (further from the core).

- If a structure $M$ is repaired within words of a given stratum, $M$ is repaired for words in all less peripheral strata (closer to the core).

Such effects have been documented for loanword adaptation patterns in a variety of languages, including Russian (Holden 1976), Turkish (Zimmer 1985), Québec French (Paradis \& Lebel 1994; Hsu \& Jesney 2017), Japanese (Itô \& Mester 1995, 1999), German (Itô \& Mester 2001), and Guaraní (Pinta 2013; Pinta \& Smith 2017). ${ }^{1}$

2.2 Subset at periphery Subset-at-periphery patterns are less commonly attested in the literature than superset-at-periphery patterns, but there are a number of well-described cases, including in Slovenian (Jurgec 2010), Hungarian (Nádasdy 1989; Magyar 2014), and colloquial Czech (Mathesius 1934; Saciuk 1969). In each of these, the language enforces restrictions on loanwords that are not enforced on more nativized vocabulary. That is, structures permitted in native words are banned in loanwords. For instance, when Hungarian borrows foreign words containing a singleton consonant after a short vowel, the consonant

\footnotetext{
${ }^{1}$ Most existing work describes this type of patterning among relatively established borrowings. This leads to the question of whether these patterns should be modeled as part of the grammar, particularly in cases where they do not appear to be associated with alternations (Inkelas et al. 1997; Burness 2016; Hearn 2017). Experimental work in on-line loanword adaptation has yielded mixed evidence for implicational restrictions (Pinta 2013). We will leave the question open for future work, and here assume that these patterns are represented within the synchronic grammar.
} 
is consistently repaired to a geminate, even though singleton consonants are permitted after short vowels in native words (Nádasdy 1989; Magyar 2014). The productivity of the process varies based on the particular vowels and consonants, but gemination applies to loanwords of various origins, independent of orthography.

$$
\begin{aligned}
& \text { Loanwords: Gemination enforced after short vowels } \\
& \text { Eng. fit }>\text { [fit:] } \\
& \text { Fr. choc }>\text { [sok:] 'shock' } \\
& \text { Native vocabulary: Contrastive consonant length } \\
& \text { [kos] 'dirt' } \sim \text { [ros:] 'bad' } \\
& {\left[\begin{array}{l}
\text { [vitse] 'janitor' } \sim[\text { vit:se] 'his/her joke' }
\end{array}\right.}
\end{aligned}
$$

Curiously, subset-at-periphery patterns are not always markedness reducing. In colloquial Czech, $/ \mathrm{k} / \mathrm{in}$ loanwords is adapted as $[\mathrm{g}]$ in word-initial, intervocalic, and liquid-adjacent positions, even though these contexts permit [k] in native words (Mathesius 1934; Saciuk 1969). The word-initial voicing pattern, in particular, is difficult to construe as a case of markedness reduction; such patterns potentially reflect a form of deliberate markedness (Tanaka \& Yashima 2013) used to call out borrowed forms.

$$
\begin{array}{ll}
\text { Loanwords: }[\mathrm{k}]>[\mathrm{g}] & \\
\text { Eng. couch }>[\mathrm{g}] \text { auc } & \text { 'couch' } \\
\text { It. balcone }>\text { bal[g]ón } & \text { 'balcony' } \\
\text { Ger. plakat }>\text { pla }[\mathrm{g}] \text { át } & \text { 'poster' }
\end{array}
$$

Native vocabulary: $[\mathrm{k}]$ surfaces
$[\mathrm{k}] a$ še $\quad$ 'pulp, mash'
pál[k]a 'bat'
pla $[\mathrm{k}] a t \quad$ 'to cry'

Crucially, while subset-at-periphery patterns are rarer than superset-at-periphery patterns, they follow a similar implicational restriction. This is true for instance in Hungarian, where relatively nativized older borrowings are less likely to undergo gemination than are new loans (Nádasdy 1989).

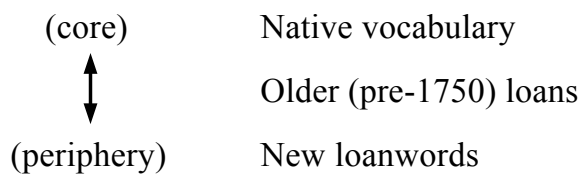

$$
\begin{aligned}
& \text { singletons and geminates contrast } \\
& \text { gemination sporadically enforced } \\
& \text { gemination enforced }
\end{aligned}
$$

For subset at periphery patterns, the implicational generalization can be stated as in (12).

(12) Superset at periphery:

- If a structure $\mathrm{M}$ is tolerated within words of a given stratum, $\mathrm{M}$ is tolerated for words in all less peripheral strata (closer to the core).

- If a structure $\mathrm{M}$ is repaired within words of a given stratum, $\mathrm{M}$ is repaired for words in all more peripheral strata (further from the core).

2.3 Divergent repair The third type of pattern we consider is divergent repair. In this case, loanwords respond to restrictions in different ways than native vocabulary, using distinct processes to repair a given marked structure. For instance, while no stratum in Japanese permits onset clusters, illicit clusters are repaired differently in different strata: consonant deletion applies in Yamato (native) vocabulary, while vowel epenthesis applies in modern loanwords (McCawley 1968; Smith 2006).

$$
\begin{aligned}
& \text { Loanwords: Vowel epenthesis } \\
& \text { Eng. cream }>\text { [ku.ri..mu] } \\
& \text { Eng. brand }>\text { [bu.ran.do] }
\end{aligned}
$$

$$
\begin{aligned}
& \text { Native vocabulary: Deletion } \\
& / \mathrm{kak}+\mathrm{rw} / \rightarrow[\mathrm{ka} . \mathrm{kw}] \text { 'write-NONPAST' } \\
& / \text { tob }+\mathrm{ru} / \rightarrow[\text { to.bu] 'fly-NONPAST' }
\end{aligned}
$$

Similarly, Oshikwanyama repairs sequences of a nasal followed by a voiceless stop through coalescence in native words, but through consonant voicing in loanwords (Steinbergs 1985). 
As with the subset-at-periphery and superset-at-periphery patterns described in the previous sections, divergent repairs patterns are strictly implicational. Distinct repairs do not apply randomly across different degrees of nativization. This can be clearly seen in the repair patterns applied to obstruent + nasal sequences in Korean. In native and mostly nativized Sino-Korean words, these sequences are repaired by obstruent nasalization, while in newer loans they are repaired by epenthesis (Kang 1996). In terms of the core-periphery structure, the repair processes apply on different sides of a single cutoff; identical repairs do not apply in non-contiguous strata.

\begin{tabular}{|c|c|c|c|}
\hline (core) & Native & /kuk-mul/ $\rightarrow$ [kummul] 'soup' & nasalization \\
\hline & Sino-Korean & /kuk-min/ $\rightarrow$ [kuymin] 'people' & nasalizatio \\
\hline (periphery) & Foreign & $/ \mathrm{p}^{\mathrm{h}} \mathrm{Iknik} / \rightarrow\left[\mathrm{p}^{\mathrm{h}}\right.$ ikinik] 'picnic' & epenthesis \\
\hline
\end{tabular}

2.4 Interim summary The literature on loanword phonology has identified a large number of factors that can influence the adaptation of foreign words, including language-specific perceptual factors (Peperkamp \& Dupoux 2003; Peperkamp et al. 2008), auditory versus orthographic modes of borrowing (Smith 2006; Daland et al. 2015), featural contrasts of the borrowing language (Paradis \& LaCharité 2001), and many others (see Kang 2011 for an overview). It is thus unsurprising that a wide range of adaptation patterns is attested. In each case, though, the effects of degree of nativization are not arbitrary. Subset-atperiphery, superset-at-periphery, and divergent repair patterns all obey the implicational restriction in (16), suggesting that this is a core property of how the phonological grammar interfaces with the lexicon.

\section{Overall implicational pattern of loanword adaptation}

If a process or restriction applies at some stratum $d$ of nativization, but fails to apply at stratum $d+$ 1 , it also fails to apply at all strata beyond $d+1$.

\section{Generating the typology with scalar constraints}

This section presents our account of the implicational patterns presented in the previous section. As we show, superset-at-periphery, subset-at-periphery, and divergent repair patterns are all predicted to emerge in a model where constraints are weighted as in Harmonic Grammar (HG; Legendre, Miyata \& Smolensky 1990; Smolensky \& Legendre 2006) and violation scores are scaled based on degree of nativization. This proposal builds on a growing body of work showing that scalar constraints within HG can be used to effectively model a wide range of influences on phonological patterning, including continuous phonetic properties (Flemming 2001; Cho 2011; McAllister Byun 2011; Ryan 2011), the abstract sonority scale (Pater 2012, 2016, Jesney 2015), trigger/target strength in vowel harmony (Kimper 2011), prosodic boundary strength (Hsu \& Jesney 2016), lexical category membership and frequency (Coetzee \& Kawahara 2013; Linzen, Kasanyenko \& Gouskova 2013), and locality in vowel harmony (Kimper 2011; McPherson \& Hayes 2016).

At the heart of our proposal is the idea that the penalty associated with violation of a constraint is scaled based on distance from the core lexicon. Here, the total penalty for a constraint violation is $w+s(d)$, where $w$ is the base constraint weight, $s$ is the scaling factor, and $d$ is a measure of distance from the core. Values for $d$ begin at 0 , in the case of words within the core lexicon, and increase as the degree of nativization decreases (cf. Linzen, Kasanyenko \& Gouskova 2013; Hsu \& Jesney 2017). General definitions for the scaled versions of Faithfulness and Markedness constraints are given in (17) and (18).

\section{Scaled Faithfulness}

Given a basic constraint weight $w$, a scaling factor $s$, and a distance from the core $d$, For each input structure that is not realized faithfully in the output, Assign a weighted violation score of $w+s(d)$ 


\author{
Scaled Markedness \\ Given a basic constraint weight $w$, \\ a scaling factor $s$, and a distance from the core $d$, \\ For each instance of the marked structure \\ Assign a weighted violation score of $w+s(d)$
}

The three types of implicational patterns discussed in the previous section emerge from the interaction of these scalar constraints. By altering the relative values of $w$ and $s$ associated with different constraints, superset-at-periphery, subset-at-periphery, and divergent repair patterns can all be effectively modeled.

3.1 Superset at periphery In general, superset-at-periphery patterns arise when two conditions hold. First, the basic weight of the relevant Markedness constraint $w(\mathrm{M})$ must be greater than the basic weight of the conflicting Faithfulness constraint $w(\mathrm{~F})$. Within the core lexicon where the value of $d$ is 0 and no scaling factor therefore applies, the penalty assigned for violating the Markedness constraint is greater than the penalty assigned for violating the Faithfulness constraint, and so the marked structure is repaired. Second, the scaling factor associated with the Faithfulness constraint $s(\mathrm{~F})$ must be greater than the scaling factor associated with the Markedness constraint $s(\mathrm{M})$. As the distance from the core and the value of $d$ increases, the overall penalty assigned for violating the Faithfulness constraint eventually exceeds the overall penalty assigned for violating the Markedness constraint, and the marked structure is realized faithfully.

Figure 2 depicts this interaction. Here, the basic weight of Markedness is $w(\mathbf{M})=4$ and the basic weight of Faithfulness is $w(\mathrm{~F})=1$. The scaling factor for Markedness is $s(\mathrm{M})=1$ and the scaling factor for Faithfulness is $s(\mathrm{~F})=3$. With these values, the penalty assigned for violation of the Markedness constraint exceeds the penalty assigned for violation of the Faithfulness constraint for all values $d<1.5$. As the periphery is approached and $d>1.5$, however, the relative penalties assigned for violations of the two constraints flip. At this point, faithful realization of the marked structure is expected.

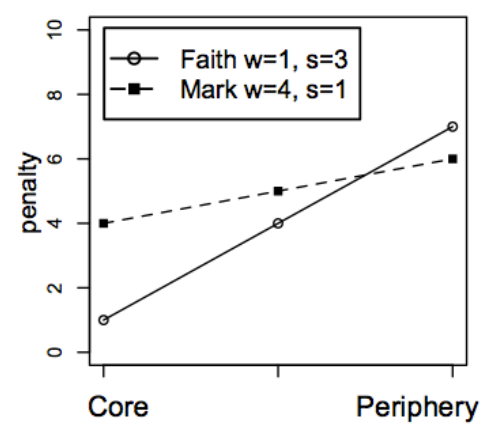

Core Faithfulness penalty $=1+3(0)=1$
Core Markedness penalty $=4+1(0)=4$
Periphery Faithfulness penalty $=1+3(2)=7$
Periphery Markedness penalty $=4+1(2)=6$

Figure 2: Sample constraint values for the superset-at-periphery pattern

Given such a configuration of weighting and scaling factors, the implicational pattern described above will hold for any marked structure. If a marked structure becomes licit at some distance $d$ from the core, then it will be licit at all distances $\geq d$. Furthermore, because only one value of $d$ can be selected on each iteration of EVAL, the nested relationship between the various marked structures is preserved.

This effect is illustrated in Figure 3 for the Oshikwanyama data discussed in section 2.1. There are two distinct superset-at-periphery patterns in Oshikwanyama, each involving a pair of conflicting Markedness and Faithfulness constraints. At the core, when $d=0$, both $[\mathrm{I}]$ and consonant clusters are repaired, yielding the mapping $/$ farm $/ \rightarrow$ [falama]. As the distance from the core increases, the relative penalties assigned by the Markedness and Faithfulness constraints involved in the cluster repair pattern - i.e., *CC and DEP-V eventually flip. Given the values in Figure 3, this occurs when $d>0.5$. At this same value of $d$, however, the penalty associated with violating ${ }^{*} \mathrm{r}$ is still greater than the penalty associated with violating FAITH-r. This combination of conditions yields the intermediate stratum mapping / farm/ $\rightarrow$ [falma]. Eventually, once $d>1.5$ and the penalty associated with violating FAITH-r exceeds the penalty associated with violating $*$ r, both marked structures are realized faithfully and /farm/ maps to [farma]. 


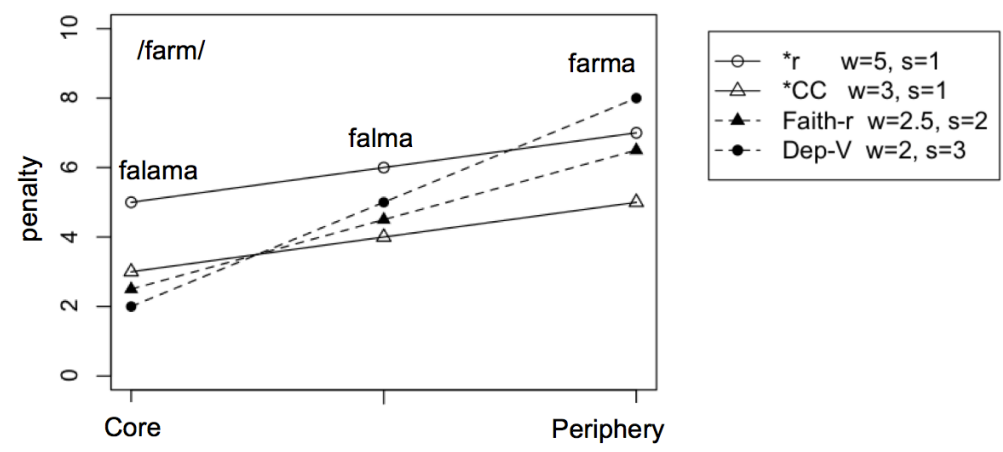

Figure 3: Oshikwanyama superset-at-periphery pattern

3.2 Subset at periphery Subset-at-periphery patterns emerge under conditions that are essentially the inverse of those that yield superset-at-periphery patterns. Here, the basic weight of the relevant Faithfulness constraint $w(\mathrm{~F})$ must be greater than the basic weight of the conflicting Markedness constraint $w(\mathrm{M})$ so that within the core lexicon the penalty assigned for violating the Faithfulness constraint is greater than the penalty assigned for violating the Markedness constraint. As a result, the marked structure is realized faithfully at the core. At the same time, the scaling factor associated with the Markedness constraint $s(\mathrm{M})$ must be greater than the scaling factor associated with the Faithfulness constraint $s(\mathrm{~F})$. As the distance from the core and value of $d$ increases, the overall penalty assigned by the Markedness constraint eventually exceeds the overall penalty assigned by the Faithfulness constraint, and the marked structure is repaired.

Figure 4 depicts this pattern. Given the weights and scaling factors of the constraints, the penalty assigned for violation of the Faithfulness constraint exceeds the penalty assigned for violation of the Markedness constraint at the core and all values $d<1.5$. Beyond this, at values $d>1.5$, the penalty assigned for violation of the Markedness constraint is greater than the penalty assigned for violation of the Faithfulness constraint, and repair of the marked structure is anticipated. ${ }^{2}$

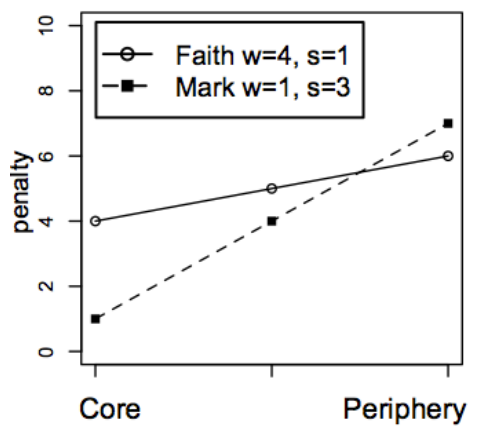

Core Faithfulness penalty $=4+1(0)=4$

Core Markedness penalty $=1+3(0)=1$

Periphery Faithfulness penalty $=4+1(2)=6$

Periphery Markedness penalty $=1+3(2)=7$

Figure 4: Sample constraint values for the subset-at-periphery pattern

For each marked structure, the implication holds. If a marked structure becomes illicit at distance $d$ from the core, then it will be illicit at all distances $\geq d$.

3.3 Divergent repairs Divergent repair patterns are modeled in a similar fashion within this framework, although the key interactions in this case involve the relative penalties of two (or more) faithfulness constraints. In general, these divergent repair patterns emerge when three conditions are present. First, there is a high-weighted Markedness constraint whose penalty for violation is consistently greater than that of the conflicting faithfulness constraints. This forces repair of the marked structure across

\footnotetext{
${ }^{2}$ In cases like the Czech velar-voicing pattern that are not clearly markedness reducing, the Markedness constraint involved is likely induced based on speakers' experience with loanword borrowing. Once induced, it must be assigned a weight and scaling factor consistent with the patterns discussed in the main text in order for a subset-at-periphery pattern to obtain.
} 
the range of values for $d$. Second, the basic weight of one conflicting Faithfulness constraint $w(\mathrm{~F} 1)$ is greater than the basic weight of a second conflicting Faithfulness constraint $w(\mathrm{~F} 2)$ so that within the core lexicon the repair that violates F2 is preferred. Finally, the scaling factor associated with the second Faithfulness constraint $s(\mathrm{~F} 2)$ is greater than the scaling factor associated with the first Faithfulness constraint $s(\mathrm{~F} 1)$ so that the overall penalty assigned by F2 eventually exceeds the overall penalty assigned by $\mathrm{F} 1$, and the alternative repair is preferred.

Figure 5 represents this configuration of values. Here, the Markedness constraint has a basic weight of $w(\mathrm{M})=7$ and a scaling factor of $s(\mathrm{M})=1$, ensuring that violating one of the Faithfulness constraints is preferable at both the core and the periphery. A value of $d>3$ would be required for the marked structure to be realized in this case. The first Faithfulness constraint - FAITH1 - has a basic weight of $w(\mathrm{~F} 1)=1$ and a scaling factor of $s(\mathrm{~F} 1)=3$, while the second faithfulness constraint - FAITH2 -has a basic weight of $w(\mathrm{~F} 2)$ $=4$ and a scaling factor of $s(\mathrm{~F} 2)=1$. The penalty assigned for violation of FAITH2 exceeds the penalty assigned for violation of FAITH1 at all values $d<1.5$. As the value of $d$ increases, however, the relative penalty assigned by the two constraints reverses and the preferred repair shifts in consequence.

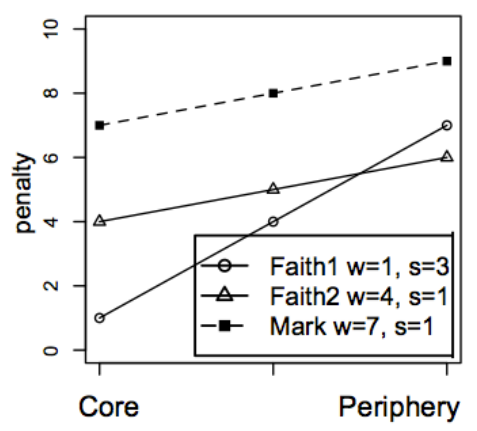

Core Markedness penalty $=7+1(0)=7$

Core Faithfulness1 penalty $=1+3(0)=1$

Core Faithfulness 2 penalty $=4+1(0)=4$

Periphery Markedness penalty $=7+1(2)=9$

Periphery Faithfulness 1 penalty $=1+3(2)=7$

Periphery Faithfulness 2 penalty $=4+1(2)=6$

Figure 5: Sample constraint values for the divergent repairs pattern

As with the other patterns discussed, the implicational nature of the divergent repair pattern emerges as a simple consequence of the values involved. If a particular repair becomes preferred at distance $d$ from the core, then it will continue to be preferred at all distances $\geq d$.

3.4 Interim summary The implicational patterns observed in loanword adaptation are captured in a straightforward fashion in a Harmonic Grammar model that allows for scalar constraints. The basic weights of the constraints are seen at the core, and their relative penalties determine the native phonological pattern. As distance from the core increases, the scaling factors associated with each constraint have the ability to alter the relative penalties assigned. While the patterns at various distances from the core can differ, the range of variation across the lexicon is constrained. Patterns involving repair and non-repair of each marked structure are strictly implicational. If a given process or restriction applies at some stratum $d$ of nativization, but fails to apply at stratum $d+1$, it also fails to apply at all strata beyond $d+1$.

\section{Ranked constraint alternatives}

In ranked constraint grammars, patterns of loanword adaptation are typically modeled in one of two ways: indexation of constraints to apply to individual lexical strata (e.g., Itô \& Mester 1999), or separate co-phonologies associated with individual lexical strata (Orgun 1996; Inkelas \& Zoll 2007). While both of these approaches are able to model the patterns discussed in this paper, preventing overgeneration is more difficult. Without metaconditions on possible constraint rerankings, either among indexed constraints or across cophonologies, the attested implicational restrictions cannot be assured. As the previous section demonstrated, no such metaconditions are needed in a Harmonic Grammar model with scalar constraints.

The basic problem for OT approaches follows from the fact that there is no necessary systematic relationship between the constraint rankings associated with different strata. If any constraint can have an indexed version for each stratum, or there is no restriction on the reranking of constraints across cophonologies, each lexical stratum can display arbitrarily different phonological patterns. Curtailing the 
predicted typology in these approaches requires limiting the set of constraints that can be indexed or reranked and placing metaconditions on possible constraint rankings. For instance, Itô \& Mester (1999, 2001) propose that implicational repair patterns in superset-at-periphery cases can be preserved if only faithfulness constraints are indexed, and these are subject to a Ranking Consistency metacondition.

(19) Ranking Consistency: Let F and G be two types of IO-faithfulness constraints (e.g., IDENTPLACE and IDENT- $\mu$ ). These are no strata A, B such that the relative rankings of the indexed versions of $\mathrm{F}$ and $\mathrm{G}$ are inconsistent with each other. If $\mathrm{F} / \mathrm{A}>>\mathrm{G} / \mathrm{A}$ for some stratum $\mathrm{A}$, then there is no stratum B such that $\mathrm{G} / \mathrm{B}>>\mathrm{F} / \mathrm{B}$. (Itô \& Mester 1999, 2001)

Ranking Consistency ensures that the relative rankings of Faithfulness constraints do not change across strata, even as they may increase or decrease in ranking with respect to conflicting Markedness constraints.

Although Ranking Consistency can effectively capture implicational restrictions in superset-atperiphery patterns, it encounters difficulties in other cases. The divergent repairs of obstruent+nasal sequences in Korean provide an example. Here, nasalization applies to native and Sino-Korean words, while epenthesis applies in newer borrowings. Modeling this pattern requires that the versions of DEP indexed to the native and Sino-Korean strata outrank the versions of IDENTNASAL indexed to the same strata, while the opposite ranking obtains for the versions of the constraints indexed to the foreign stratum. Such an analysis is ruled out by Ranking Consistency because it directly reverses the relative rankings of Faithfulness constraints across strata.
a. Ranking for native stratum: *OBSNAS $\gg>$ DEP $_{\mathrm{NATIVE}}>>$ IDENTNASAL $_{\mathrm{NATIVE}}$
nasalization
b. Ranking for Sino-Korean: *OBSNAS $>>$ DEP $_{\text {SINo-Kor }}>>$ IDENTNASAL $_{\text {SINo-Kor }}$
nasalization
c. Ranking for foreign stratum: *OBSNAS $>>$ IDENTNASAL $_{\text {ForelGN }}>>$ DEP $_{\text {ForeIGN }}$
epenthesis

The solution is not as simple as removing all restrictions on possible rerankings across strata, however. If constraints can be freely reranked, non-implicational Korean' patterns, where a given repair applies in non-contiguous strata, are predicted to occur.
Non-implicational Korean' divergent repair (unattested)

\begin{tabular}{|c|c|c|}
\hline (core) & Native: & /kuk-mul/ $\rightarrow[\mathrm{kummul}]$ 'soup' \\
\hline & Sino-Korean: & /kuk-min/ $\rightarrow[$ kukimin $]$ 'people' \\
\hline eriphery) & Foreign: & $/ \mathrm{p}^{\mathrm{h}} \mathrm{iknik} / \rightarrow\left[\mathrm{p}^{\mathrm{h}}\right.$ innik $]$ 'picnic' \\
\hline
\end{tabular}
nasalization
epenthesis
a. Ranking for native stratum: *OBSNAS $>>$ DEP $_{\text {Native }}>>$ IDENTNASAL $_{\text {Native }}$
b. Ranking for Sino-Korean: *OBSNAS $>>$ IDENTNASAL $_{\text {SINo-Kor }}>>$ DEP $_{\text {SINo-Kor }}$
c. Ranking for foreign strata: ${ }^{*}$ OBSNAS $>>$ DEP $_{\text {ForeIGN }}>>$ IDENTNASAL ForeIGN
nasalization
nasalization
epenthesis
nasalization

The problem also cannot be eliminated by applying a fixed ranking to each indexed series of constraints. For instance, the problematic pattern in (21) is consistent with rankings where all Foreign-indexed constraints dominate all Sino-Korean-indexed constraints, which in turn dominate all Native-indexed constraints.

$$
\begin{aligned}
& \text { *OBSNAS }>>\text { DEP ForeIGN }_{\text {Fid }}>>\text { IDENTNASAL }_{\text {ForeIGN }}>> \\
& \text { IDENTNASAL }_{\text {SINo-KoR }}>>\operatorname{DEP}_{\text {SINO-KoR }}>> \\
& \text { DEP }_{\text {Native }}>>\text { IDENTNASAL }_{\text {NATIVE }}
\end{aligned}
$$

Ultimately, generating strictly-implicational superset-at-periphery, subset-at-periphery, and divergentrepair patterns within a ranked-constraint system requires a metacondition that ensures only one reversal in the relative ranking of a conflicting constraint pair while moving from core to periphery. The relevant metaconditions for the indexed constraint and cophonology approaches are given in (23) and (24). Here, F and $\mathrm{G}$ can refer to either repair-favoring or repair-disfavoring constraints. 
(23) For indexed constraints: If indexed $F>P$ at stratum $A$ and indexed $G \gg P F$ at stratum B, where $\mathrm{B}$ is a more peripheral stratum, indexed $\mathrm{G}>\mathrm{F}$ in all strata more peripheral than $\mathrm{B}$.

(24) For cophonologies: If $F>$ G in cophonology A and $G>P$ in cophonology B, where B is associated with a more peripheral stratum, $\mathrm{G}>\mathrm{F}$ in all cophonologies associated with strata more peripheral than B.

The same implicational generalizations are predicted in the HG scalar constraint approach without need for a corresponding metacondition. All that is required is for constraint weights to be scaled monotonically based on distance from the core. Furthermore, the HG approach is readily extended to other phonological dimensions that show similar implicational cutoff effects (e.g., Hsu \& Jesney 2016; McPherson \& Hayes 2016).

\section{Conclusion}

This paper has argued that three primary patterns of loanword adaptation are captured straightforwardly in Harmonic Grammar if Markedness and Faithfulness constraint penalties can be scaled based on a lexical item's degree of nativization $d$. While degree of nativization has long been recognized as a factor in determining phonological patterns (Saciuk 1969; Holden 1976), prior accounts implement this insight only indirectly; here, degree of nativization is incorporated directly as a variable in the grammar. As a result, this approach is able to accommodate fine-grained effects of relative nativization without needing to proliferate the number of indexed constraints or cophonologies - a particular benefit when degree of nativization does not correspond clearly to a limited set of strata (Hsu \& Jesney 2017). Implicational patterns of repair versus non-repair arise from basic patterns of constraint interaction under minimal assumptions about scaling, obviating any need for the types of metaconditions required in ranked-constraint alternatives. The result is a simple and testable model that makes clear predictions about the kinds of loanword adaptation patterns that should be observed across the languages of the world.

\section{References}

Burness, Phillip. 2016. Unproductive alternations and allomorph storage: The case of Sino-Japanese. Journal of Japanese Linguistics 32: 74-94.

Cho, Hyesun. 2011. The timing of phrase-initial tones in Seoul Korean: a weighted-constraint model. Phonology 28: 293-330.

Coetzee, Andries W. \& Shigeto Kawahara. Frequency biases in phonological variation. Natural Language and Linguistic Theory 31: 47-89.

Daland, Robert, Mira Oh \& Syejeong Kim. 2015. When in doubt, read the instructions: Orthographic effects in loanword adaptation. Lingua 159: 70-92.

Davidson, Lisa \& Rolf Noyer. 1997. Loan phonology in Huave: Nativization and the ranking of faithfulness constraints. In Proceedings of the 15th West Coast Conference on Formal Linguistics, 65-79.

Flemming, Edward. 2001. Scalar and categorical phenomena in a unified model of phonetics and phonology. Phonology 18: 7-44.

Hearn, Ryan. 2017. Rethinking lexical indexing models: evidence from Japanese and English. Poster presented at the $91^{\text {st }}$ Annual Meeting of the Linguistic Society of America, Austin, Texas, Jan. 5-8.

Holden, Kyril. 1976. Assimilation rates of borrowings and phonological productivity. Language 52: 131-147.

Hsu, Brian \& Karen Jesney. 2016. Scalar positional markedness and faithfulness in Harmonic Grammar. In Proceedings of the 51st Annual Meeting of the Chicago Linguistic Society, 241-255. Chicago: Chicago Linguistic Society.

Hsu, Brian \& Karen Jesney. 2017. Loanword adaptation in Québec French : Evidence for Weighted Scalar Constraints. In Proceedings of the 34th West Coast Conference on Formal Linguistics, eds. Aaron Kaplan, Abby Kaplan, Miranda K. McCarvel \& Edward J. Rubin, 249-258. Somerville, MA: Cascadilla.

Inkelas, Sharon, Cemil Orhan Orgun \& Cheryl Zoll. 1997. The implications of lexical exceptions for the nature of grammar. In Derivations and constraints in phonology, ed. Iggy Roca, 393-418. Oxford: Clarendon Press.

Inkelas, Sharon \& Cheryl Zoll. 2007. Is Grammar Dependence Real? A comparison between cophonological and 
indexed constraint approaches to morphologically conditioned phonology. Linguistics 45: 133-171.

Itô, Junko \& Armin Mester. 1995. The core-periphery structure of the lexicon and constraints on reranking. In Papers in Optimality Theory, eds. Jill Beckman, Sue Urbanczyk \& Laura Walsh Dickey, 181-209. Amherst, MA: GLSA.

Itô, Junko \& Armin Mester. 1999. The structure of the phonological lexicon. In The handbook of Japanese Linguistics, ed. Natsuko Tsujimura, 62-100. Malden, MA: Blackwell.

Itô, Junko \& Armin Mester. 2001. Covert generalizations in Optimality Theory: the role of stratal faithfulness constraints. Studies in Phonetics, Phonology, and Morphology 7: 273-299.

Jesney, Karen. 2015. Counterbled-counterfeeding in Harmonic Grammar. In Proceedings of the 45 ${ }^{\text {th }}$ Meeting of the North East Linguistic Society (NELS 45), Vol. 2, eds. Thuy Bui \& Deniz Özy1ldız, 59-72. Amherst, MA: GLSA.

Jurgec, Peter. 2010. Disjunctive lexical stratification. Linguistic Inquiry 41: 149-161.

Kang, Yoonjung. 2011. Loanword phonology. In The Blackwell companion to phonology, eds. Marc van Oostendorp, Colin Ewen, Elizabeth Hume \& Keren Rice, 2258-2282. Malden, MA: Wiley-Blackwell.

Kenstowicz, Michael. 2005. The phonetics and phonology of Korean loanword adaptation. In Proceedings of ECKL 1: Proceedings of 1st European Conference on Korean Linguistics, ed. S.-J. Rhee, 17-32. Seoul: Hankook Publishing Co.

Kenstowicz, Michael \& Atiwong Suchato. 2006. Issues in loanword adaptation: A case study from Thai. Lingua 116: 921-949.

Kimper, Wendell. 2011. Competing triggers: transparency and opacity in vowel harmony. PhD dissertation, University of Massachusetts Amherst.

Legendre, Géraldine, Yoshiro Miyata \& Paul Smolensky. 1990. Can connectionism contribute to syntax?: Harmonic Grammar, with an application. In Proceedings of $26^{\text {th }}$ Annual Meeting of the Chicago Linguistic Society, eds. M. Ziolkowski, M. Noske, \& K. Deaton, 237-252. Chicago: Chicago Linguistic Society.

Linzen, Tal, Sofya Kasyanenko \& Maria Gouskova. 2013. Lexical and phonological variation in Russian prepositions. Phonology 30: 453-515.

Magyar, Lilla. 2014. Gemination in Hungarian loanword adaptation. Ms., Massachusetts Institute of Technology.

McAllister Byun, Tara. 2011. A gestural account of a child-specific neutralisation in strong position. Phonology 28: 371-412.

Mathesius, Vilém. 1934. Zur synchronischen Analyse fremden Sprachguts. Englische Studien 70: 21-35.

McPherson, Laura \& Bruce Hayes. 2016. Relating application frequency to morphological structure: the case of Tommo So vowel harmony. Phonology 33.

Nádasdy, Ádám. 1989. Consonant length in recent borrowings into Hungarian. Acta Linguistica Hungarica 39: 195213.

Orgun, Cemil Orhan. 1996. Sign-based morphology and phonology: with special attention to Optimality Theory. Ph.D dissertation, University of California, Berkeley.

Paradis, Carole \& Darlene LaCharité. 1997. Preservation and minimality in loanword adaptation. Journal of Linguistics 33: 379-430.

Paradis, Carole \& Darlene LaCharité. 2001. Guttural deletion in loanwords. Phonology 18: 255-300.

Paradis, Carole \& Caroline Lebel. 1994. Contrasts from segmental parameter settings in loanwords: core and periphery in Quebec French. In Proceedings of the MOT Conference on Contrast in Phonology, 75-95. Department of Linguistics, University of Toronto.

Pater, Joe. 2012. Serial Harmonic Grammar and Berber syllabification. In Prosody matters: essays in honor of Elisabeth O. Selkirk, eds. Toni Borowsky, Shigeto Kawahara, Takahito Shinya \& Mariko Sugahara, 43-72. London: Equinox Press.

Pater, Joe. 2016. Universal Grammar with weighted constraints. In Harmonic Grammar and Harmonic Serialism, eds. John J. McCarthy \& Joe Pater, 1-46. London: Equinox Press.

Peperkamp, Sharon \& Emmanuel Dupoux. 2003. Reinterpreting loanword adaptations: the role of perception. Proceedings of the 15th International Congress of Phonetic Sciences: 367-370.

Peperkamp, Sharon, Inga Vendelin \& Kimihiro Nakamura. 2008. On the perceptual origin of loanword adaptations: experimental evidence from Japanese. Phonology 25: 129-164.

Pinta, Justin. 2013. Lexical strata in loanword phonology: Spanish loans in Guaraní. Masters thesis, University of North Carolina at Chapel Hill.

Pinta, Justin \& Jennifer L. Smith. 2017. Spanish loans and evidence for stratification in the Guaraní lexicon. In Guarani linguistics in the 21st century, eds. Bruno Estigarríbia \& Justin Pinta, 285-314. Leiden: Brill. 
Prince, Alan \& Paul Smolensky. 2004 [1993]. Optimality Theory: Constraint interaction in generative grammar. Malden, MA: Blackwell.

Ryan, Kevin. 2011. Gradient syllable weight and weight universals in quantitative metrics. Phonology 28: $413-454$.

Saciuk, B. 1969. The stratal division of the lexicon. Linguistics 1: 464-532.

Smith, Jennifer L. 2006. Loan phonology is not all perception: evidence from Japanese loan doublets. In Japanese/Korean Linguistics 14, eds. Timothy J. Vance \& Kimberly Jones, 63-74. Stanford: CSLI Publications.

Smolensky, Paul \& Géraldine Legendre. 2006. The Harmonic Mind: From Neural Computation to OptimalityTheoretic Grammar. Cambridge, MA: MIT Press.

Steinbergs, Aleksandra. 1985. The role of MSC's in Oshikwanyama loan phonology. Studies in African Linguistics 16: 89-101.

Tanaka, Yu \& Jun Yashima. 2013. Deliberate markedness in Japanese hypocoristics. Proceedings of GLOW in Asia IX: 283-297.

Zimmer, Karl. 1985. Arabic loanwords and Turkish phonological structure. International Journal of American Linguistics 51: 623-625. 